\title{
The Effects of Diosgenin on Hypolipidemia and Its Underlying Mechanism: A Review
}

\author{
Fengcui Sun' \\ Xiufen Yang' \\ Chaoqun $\mathrm{Ma}^{\prime}$ \\ Shizhao Zhang' \\ Lu Yu ${ }^{2}$ \\ Haifei Lu ${ }^{3}$ \\ Guoliang Yin' \\ Pengpeng Liang' \\ Yanan Feng' \\ Fengxia Zhang $\mathbb{D}^{4}$
}

'Shandong University of Traditional Chinese Medicine, Jinan, 250000, People's Republic of China; ${ }^{2}$ Tianjin University of Traditional Chinese Medicine, Tianjin, 301617, People's Republic of China;

${ }^{3}$ Hubei University of Traditional Chinese Medicine, Wuhan, 430065, People's Republic of China; ${ }^{4}$ Department of Neurology, Affiliated Hospital of Shandong University of Traditional Chinese Medicine, Jinan, 2500I I, People's Republic of China
Correspondence: Fengxia Zhang Department of Neurology, Affiliated Hospital of Shandong University of Traditional Chinese Medicine, Jinan, 2500I I, People's Republic of China $\mathrm{Tel}+8653168616011$

Email fxzhang0987@I63.com

\begin{abstract}
Hyperlipidemia is a disorder of lipid metabolism, which is a major cause of coronary heart disease. Although there has been considerable progress in hyperlipidemia treatment, morbidity and risk associated with the condition continue to rise. The first-line treatment for hyperlipidemia, statins, has multiple side effects; therefore, development of safe and effective drugs from natural products to prevent and treat hyperlipidemia is necessary. Diosgenin is primarily derived from fenugreek (Trigonella foenum graecum) seeds, and is also abundant in medicinal herbs such as Dioscorea rhizome, Dioscorea septemloba, and Rhizoma polygonati, is a well-known steroidal sapogenin and the active ingredient in many drugs to treat cardiovascular conditions. There is abundant evidence that diosgenin has potential for application in correcting lipid metabolism disorders. In this review, we evaluated the latest evidence related to diosgenin and hyperlipidemia from clinical and animal studies. Additionally, we elaborate the pharmacological mechanism underlying the activity of diosgenin in treating hyperlipidemia in detail, including its role in inhibition of intestinal absorption of lipids, regulation of cholesterol transport, promotion of cholesterol conversion into bile acid and its excretion, inhibition of endogenous lipid biosynthesis, antioxidation and lipoprotein lipase activity, and regulation of transcription factors related to lipid metabolism. This review provides a deep exploration of the pharmacological mechanisms involved in diosgenin-hyperlipidemia interactions and suggests potential routes for the development of novel drug therapies for hyperlipidemia.
\end{abstract}

Keywords: diosgenin, hyperlipidemia, serum cholesterol, lipoprotein cholesterol, mechanism

\section{Introduction}

Hyperlipidemia is a pathological disorder of lipid metabolism that has various causes. The clinical manifestations of hyperlipidemia include increased serum cholesterol, triglycerides, and low-density lipoprotein cholesterol (LDL-C), and decreased serum high-density lipoprotein cholesterol (HDL-C). Imbalance of LDL-C and HDL-C can increase the risk of cardiovascular (CV) events, including myocardial infarction and stroke. ${ }^{1}$ Data released by the American Heart Association in 2018 showed that CV disease (CVD) is the most lethal disease worldwide. ${ }^{2}$ According to the 2010 global burden of disease study, 15.6 million people died of CVD, accounting for $29.6 \%$ of all deaths. ${ }^{3}$ Hyperlipidemia has a long disease course, and many underlying causes, reflecting its complex etiology. 4 Dyslipidemia is a significant risk factor for coronary artery disease and stroke; hence, prevention and appropriate management of dyslipidemia can markedly lower the related morbidity and mortality. ${ }^{5}$ Holven et al described the importance of early 
identification and treatment of patients with familial hypercholesterolemia for reducing cholesterol burden and risk of CHD. ${ }^{6}$ Lipid-lowering therapy is a cornerstone of $\mathrm{CV}$ risk modification strategies, which can reduce LDL-C by $30-50 \%$ and proportionally reduce $\mathrm{CV}$ events. ${ }^{7}$ Although statins are generally well tolerated, they are not always sufficient to achieve LDL-C goals for many patients, and cause numerous specific negative effects on muscle, liver, and kidney, as well as increasing the risk of new-onset diabetes mellitus and hemorrhagic stroke. ${ }^{8,9}$ Therefore, there is an urgent need to develop new powerful drugs to treat hyperlipidemia and reduce the harms to human health and longevity worldwide associated with CV events.

Natural products can facilitate a multi-component, multi-target, multi-channel, and multi-dimensional overall treatment networks. ${ }^{10}$ Thus, natural products represent alternative resources for developing new drugs, with higher efficiency, better safety, and fewer side effects. ${ }^{11}$ Moreover, natural products can play essential roles in preventing and treating many human diseases, including CVDs, metabolic syndromes, cancer, diabetes, obesity, and neurological disorders. ${ }^{12,13}$

Diosgenin, a well-known steroid sapogenin, occurs widely in various medical plants, ${ }^{14}$ and is mainly isolated from Dioscoreaceae, Agavaceae, Amaryllidaceae, Liliaceae, Solanaceae, Scrophulariaceae, Amaryllidaceae, Leguminosae, and Rhamnaceae. ${ }^{15}$ The best-known source of various steroidal saponins, including spirostane and furostane types, is fenugreek (Trigonella foenum graecum) seeds. ${ }^{16}$ In recent years, diosgenin has attracted increasing attention due to its efficacy in treating various metabolic diseases, including diabetes, ${ }^{17}$ CVDs,${ }^{18}$ neurological disease, ${ }^{19}$ osteoporosis, ${ }^{20}$ and hyperlipidemia, ${ }^{21}$ in addition to anti-cancer effects, which are mediated via multiple targets and regulate various signals. ${ }^{22,23}$ Numerous animal experiments and clinical trials have shown that diosgenin can reduce blood lipids by lowering plasma low-density lipoprotein (LDL) and increasing highdensity lipoprotein (HDL). Cholesterol lowering drug cholestyramine can combine with bile acid (BA) to form insoluble complex and prevent its reabsorption. Compared with the impact of cholestyramine, diosgenin can interfere with the absorption of exogenous and endogenous cholesterol, promote the secretion of cholesterol into bile, and increase the excretion of neutral sterols without affecting the bile and fecal excretion of bile acid. ${ }^{24}$ The effect of diosgenin combined with clofibrate in reducing plasma LDL is more robust than that of a single drug; hence, diosgenin can be combined with other lipid- lowering medications to enhance their effects. ${ }^{25}$ Further, diosgenin has demonstrated outstanding potential for lowering lipids in clinical trials and animal experiments and represents a new avenue of exploration for achieving lipid reduction.

In this paper, we elaborate the detailed mechanism underlying lipid metabolism regulation by diosgenin. As shown in Figure 1, this includes the effects of diosgenin in inhibiting intestinal lipid absorption, regulating cholesterol transport, promoting cholesterol conversion into bile acid and its excretion, inhibiting endogenous lipid biosynthesis, antioxidation effects, regulating lipoprotein lipase activity, and regulating transcription factors related to lipid metabolism.

\section{Physicochemical Properties of Diosgenin}

Diosgenin (3ß-Hydroxy-5-spirostene) (Figure 2) is a C27 spironosteroidal saponin of the spirosterol steroid family that participates in various physiological and biochemical activities. Diosgenin is structurally similar to cholesterol and other steroids, with molecular formula $\mathrm{C}_{27} \mathrm{H}_{42} \mathrm{O}_{3}$, density $1.1 \pm 0.1 \mathrm{~g} / \mathrm{cm}^{3}$, and relative molecular mass 414.63. Diosgenin is the primary precursor of various pharmacologically active steroids, including corticosteroids and oral contraceptives and takes the form of a white acicular crystal or light amorphous powder, which is thermally and chemically stable under various physical conditions. The melting point of diosgenin is above $200^{\circ} \mathrm{C}$ and the compound is relatively stable under light, but unstable under hydrochloric acid, which causes its rapid decomposition. ${ }^{26}$ Diosgenin has low solubility, due to its strong hydrophobicity; its solubility in water is approximately $0.7 \mathrm{ng} / \mathrm{mL} .{ }^{27}$ Nevertheless, it is highly soluble in most nonpolar organic solvents (such as chloroform, dichloroethane, propanol, ethyl acetate, and propyl acetate) and some polar solvents (including acetone, methanol, and anhydrous ethanol). ${ }^{28}$

\section{Sources of Diosgenin}

Diosgenin is a natural steroidal saponin, which is derived from the hydrolysis of dioscin. Diosgenin can be commercially extracted from several plants, including Trigonella, ${ }^{29}$ Costus,${ }^{30}$ Aletris, Smilax,${ }^{31}$ and many species of Dioscorea. ${ }^{32}$ The primary source of diosgenin is fenugreek seeds. ${ }^{29}$ The content of saponins in fenugreek seeds is $169 \mathrm{~g} / \mathrm{kg}$. After hydrolysis for $1 \mathrm{~h}$, the saponins are completely removed and sapogenin release is maximal. 


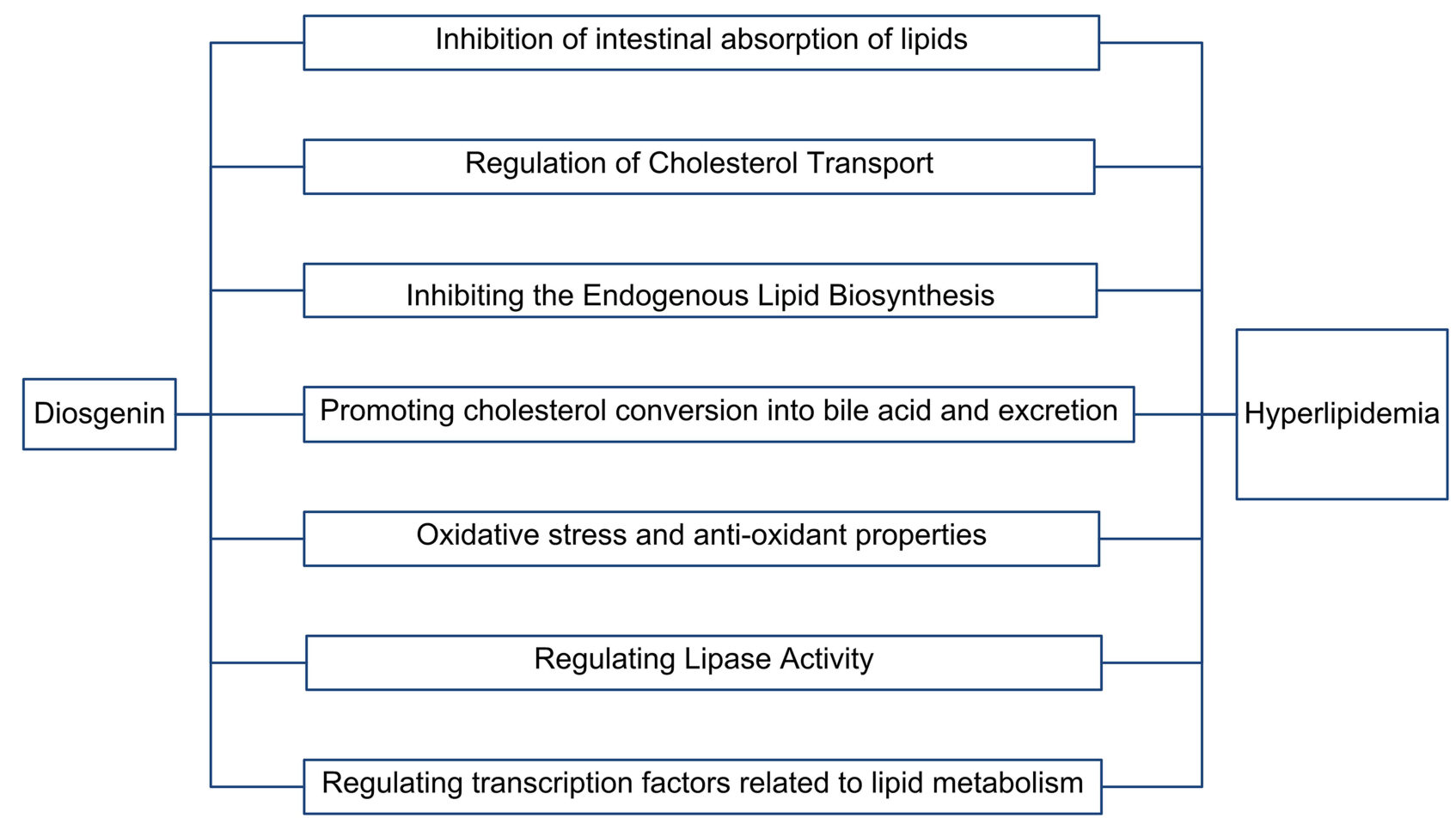

Figure I The mechanism of diosgenin on lipid metabolism. As Figure I shows, the paper will elaborate the lipid metabolism regulating mechanism of diosgenin in detail. It includes diosgenin's effects on inhibiting intestinal absorption of lipids, regulation of cholesterol transport, promoting cholesterol conversion into bile acid and excretion, inhibiting the endogenous lipid biosynthesis, effect on antioxidation, regulating lipoprotein lipase activity, and regulating transcription factors related to lipid metabolism.

Extracts of hydrolyzed fenugreek and quinoa contain the highest fraction of sapogenin and minor fractions of phytosterol and tocopherol. ${ }^{33}$ Diosgenin is an important material for the synthesis of steroid hormone medicines. For example, dehydroepiandrosterone can be produced semisynthetically from natural precursors, primarily diosgenin. $^{34}$ Traditionally, diosgenin has been extracted from the rhizome of Dioscorea zingiberensis C. H. Wright by acid hydrolysis. More recently, a new method of direct penicillin biotransformation, that is

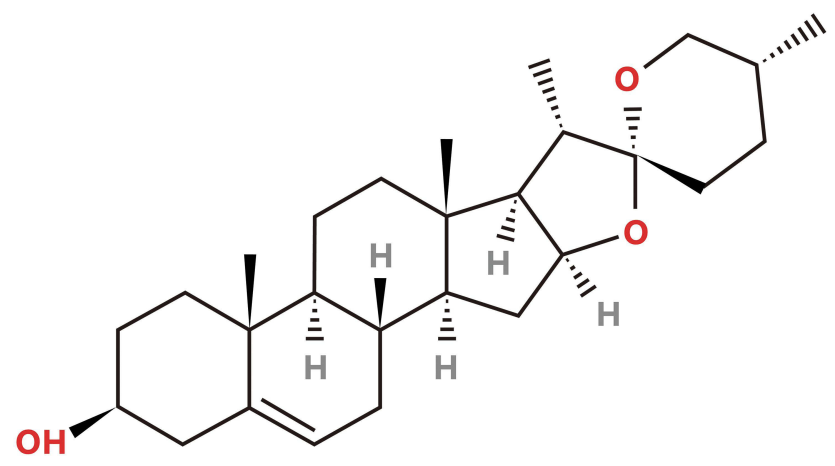

Figure 2 Chemical structure of diosgenin. Its molecular formula is $\mathrm{C}_{27} \mathrm{H}_{42} \mathrm{O}_{3}$, density is $1.1 \pm 0.1 \mathrm{~g} / \mathrm{cm}^{3}$, and relative molecular mass is 414.63 . environmental-friendly, simple, and energy-saving, has been developed and is considered a potential substitute for acid hydrolysis in the diosgenin extraction industry. ${ }^{35}$

\section{The Pharmacological Mechanism Underlying the Use of Diosgenin for Treatment of Hyperlipidemia}

Diosgenin has numerous pharmacological effects, including anti-tumor activity, improving $\mathrm{CV}$ function, regulating immunity, causing anti-platelet aggregation, and lowering blood lipids. $^{22}$ In recent years, the lipid-regulating function of diosgenin has attracted increasing attention among researchers. In humans, lipid homeostasis is regulated by homeostatic intestinal absorption mechanisms, endogenous lipid biosynthesis and metabolism, cholesterol transport, cholesterol conversion to bile acid, and biliary excretion. The metabolic enzymes and receptors involved in lipid metabolism are regulated by various transcription factors. The function of diosgenin in treating hypolipidemia through regulating the dynamics of different parts of the metabolic cycle is illustrated in Figure 3. The experimental design, pharmacological evidence, and potential mechanism of diosgenin against hyperlipidemia are summarized in Table 1. 


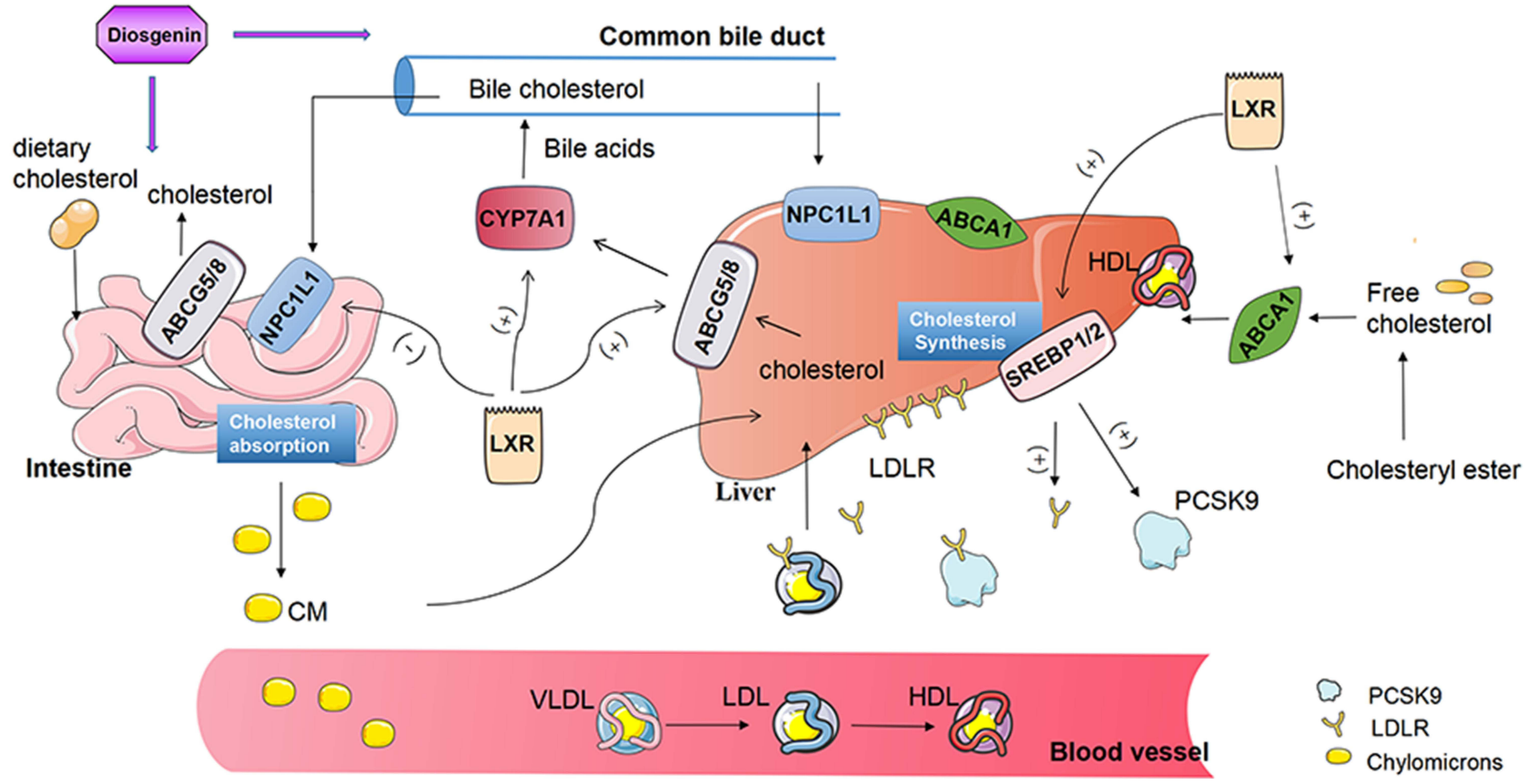

Figure 3 Schematic representation of molecular mechanisms of diosgenin attenuates cholesterol metabolism. As shown in the figure, diosgenin can inhibit cholesterol intake of human liver and intestinal cells mediated by NPCILI. Diosgenin regulates lipid homeostasis by inhibiting the expression of a series of enzymes needed by SREBPs to affect endogenous cholesterol, fatty acid, triglyceride and phospholipid synthesis. LDLR is the transcriptional target of SREBP2, diosgenin can enhance LDLR mediated uptake of cholesterol by peripheral cells from the circulation. Notably, Diosgenin may also inhibit PCSK9 mediated lysosomal degradation of PCSK9-LDLR complex and avoid LDL accumulation in vivo. Diosgenin can promote ABCAI mediated RCT process, promote cellular efflux of phospholipids and cholesterol to lipid-poor apolipoproteinA-I (apoA-I) and removal of excess cholesterol. ABCG 5/G 8 is activated by diosgenin, which promotes the secretion of unesterified free cholesterol into the bile canaliculus or gut lumen for fecal excretion and prevents the accumulation of sterols in diet. In addition, CYP7AI was activated by diosgenin to catalyze the conversion of accumulated cholesterol to primary bile acids in liver. At present, whether diosgenin can regulate cholesterol metabolism through LXRs is not very clear. $(+)$ promotion, $(-)$ inhibition.

\section{Inhibition of Intestinal Lipid Absorption}

Intestinal absorption from the diet is an important source of serum lipids. Cholesterol absorption is a key regulation target of lipid metabolism in humans, because it determines the amount of endogenous bile and cholesterol retained in the diet, thus affecting cholesterol homeostasis. Fenugreek seeds containing diosgenin induced a significant reduction of plasma cholesterol in diabetic dogs, associated with interference in cholesterol absorption. ${ }^{36}$ Further, an in vivo experiment showed that intraperitoneal injection of $0.5 \mathrm{mg} / \mathrm{kg}$ protodioscin, a steroidal saponin similar to diosgenin from Dioscorea nipponica rhizomes, could significantly reduce blood cholesterol by $40 \%$ in male Sprague-Dawley (SD) rats fed a high-fat diet (HFD) ${ }^{37}$ Researchers also investigated the inhibitory effect of diosgenin on lipid absorption using experiments on cynomolgus macaques. The macaques were fed a semi-purified diet containing $0.1 \%$ cholesterol or a similar diet containing $1 \%$ diosgenin during two 3-week periods, and received a standard chow diet for 5 weeks between the two experimental periods. The results showed that diosgenin reduced cholesterol from 292 to
$172 \mathrm{mg} / \mathrm{dl}$ and intestinal absorption of exogenous cholesterol from $62.4 \%$ to $26.0 \%$, as well as increasing net endogenous cholesterol secretion from -0.8 to $93.5 \mathrm{mg} /$ day. ${ }^{38}$ Niemann-Pick C1-Like 1 (NPC1L1) is a polytopic transmembrane protein with a critical role in cholesterol absorption. Blocking NPC1L1 endocytosis significantly reduces cholesterol endocytosis ${ }^{39}$ and hepatic NPC1L1 has a direct role in regulating bile cholesterol excretion and hepatic/blood cholesterol levels. ${ }^{40}$ Expression of NPC1L1 in the 0.15 or $0.3 \mathrm{~g} / \mathrm{kg}$ diosgenin group showed a dose-dependent decrease compared with the HFD group, demonstrating that diosgenin could reduce intestinal absorption by inhibiting NPC1L1. ${ }^{21}$ Both diosgenin and total saponins of yellow yam can significantly reduce blood cholesterol content, where the absolute dose of diosgenin comprises only half of the total saponins in yellow yam. The anti-hypercholesterolemia effect of diosgenin was superior to that of total saponins from yellow yam, likely because the polarity and spatial structure of diosgenin are very similar to those of cholesterol, suggesting that diosgenin can likely be dispersed into metacolloidals via bile acid activity, and then absorbed directly by 
Table I The Effect of Diosgenin on Markers Relevant to Lipid Metabolism

\begin{tabular}{|c|c|c|c|c|c|}
\hline Model & Diosgenin Dose & Duration & $\begin{array}{l}\text { Effects on the Plasma } \\
\text { Lipid Profile and } \\
\text { Transcription Factors }\end{array}$ & Pharmacological Effect & Reference \\
\hline HFD $^{A}$ Male $S D^{B}$ rats & $\begin{array}{l}\text { Protodioscin } \\
(0.5 \mathrm{mg} / \mathrm{kg} / \mathrm{d}) \text {; } \\
\text { intraperitoneal } \\
\text { injection }\end{array}$ & I5-28 days & $\begin{array}{l}\mathrm{TC} \downarrow, \mathrm{LDL} \downarrow, \mathrm{HDL} \downarrow, \mathrm{HDL} / \\
\mathrm{LDL} \uparrow\end{array}$ & $\begin{array}{l}\text { Inhibited HMG-CoA reductase } \\
\text { on endoplasmic reticulum }\end{array}$ & [37] \\
\hline HFD SPFC Male SD rats & $\begin{array}{l}0.15,0.3 \mathrm{~g} / \mathrm{kg} / \mathrm{d} \\
\text { intragastrically }\end{array}$ & $\begin{array}{l}4 \text { or } 8 \\
\text { weeks }\end{array}$ & $\begin{array}{l}\text { FTC } \downarrow, T T C \downarrow, T C \downarrow, T G \downarrow, \\
\text { LDL-C } \downarrow \\
\text { NPCILI } \downarrow, \text { ABCG } 5 \uparrow, \\
\text { ABCG8 } \uparrow, \text { LXR- } \alpha \downarrow\end{array}$ & $\begin{array}{l}\text { Ameliorated hepatic steatosis } \\
\text { and decreased the villi height } \\
\text { and tunica mucosa thickness; } \\
\text { Reduced cholesterol } \\
\text { absorption; Increased } \\
\text { cholesterol excretion }\end{array}$ & {$[21]$} \\
\hline $\mathrm{HCD}^{\mathrm{D}}$ Male Wistar rats & $0.5 \mathrm{~g} / \mathrm{l00g}$ orally & 4 weeks & $\begin{array}{l}\mathrm{TC} \downarrow, \mathrm{TG} \downarrow, \mathrm{HDL}-\mathrm{C} \uparrow, \mathrm{LDL}- \\
\mathrm{C} \downarrow\end{array}$ & $\begin{array}{l}\text { Reduced Cholesterol } \\
\text { absorption in the intestine and/ } \\
\text { or increased Cholesterol } \\
\text { excretion from the liver; } \\
\text { Increased bile acid and } \\
\text { Cholesterol excretions }\end{array}$ & [44] \\
\hline $\mathrm{STZ}^{\mathrm{E}}$ Male Wistar rats & $40 \mathrm{mg} / \mathrm{kg}$ b.w. orally & 45 days & $\begin{array}{l}\text { TC } \downarrow \text {, TG } \downarrow \text {, Phospholipids } \downarrow \text {, } \\
\text { FFA } \downarrow, \text { HMGR } \downarrow\end{array}$ & Decreased cholesterol synthesis & [52] \\
\hline HFD+ STZ Male SD rats & $\begin{array}{l}40,80 \mathrm{mg} / \mathrm{kg} \text { b.w. } \\
\text { orally }\end{array}$ & I4 days & $\begin{array}{l}\text { TC } \downarrow, \text { TG } \downarrow, \text { SOD } \uparrow, \text { GPX } \uparrow, \\
\text { GSH } \uparrow, \text { TBARS } \downarrow, \text { PPAR } \gamma \uparrow, \\
\text { PPAR } \alpha \uparrow\end{array}$ & $\begin{array}{l}\text { Promoted pre-adipocytes } \\
\text { differentiate; Antioxidation } \\
\text { modulating oxidative stress }\end{array}$ & [68] \\
\hline HFD Male SD rats & $\begin{array}{l}22.1,44.2,88.4 \mathrm{mg} / \\
\mathrm{kg} / \mathrm{d} \text { orally }\end{array}$ & 6 weeks & $\begin{array}{l}\mathrm{TC} \downarrow, \mathrm{TG} \downarrow, \mathrm{LDL}-\mathrm{C} \downarrow, \mathrm{GSH}- \\
\mathrm{PX} \uparrow, \mathrm{NOS} \uparrow, \mathrm{MDA} \downarrow, \mathrm{SOD} \uparrow \\
\mathrm{LPL} \uparrow, \mathrm{HL} \uparrow\end{array}$ & $\begin{array}{l}\text { Antioxidation and modulating } \\
\text { oxidative stress; Attenuated } \\
\mathrm{H} 2 \mathrm{O} \text {-induced cytotoxicity and } \\
\text { increased the cell viability; } \\
\text { Accelerated lipids metabolism; } \\
\text { Decreased cholesterol } \\
\text { absorption and increased biliary } \\
\text { cholesterol secretion; }\end{array}$ & [74] \\
\hline HFD Male C57 mice & $\begin{array}{l}\text { In drinking water, } \\
5 \mathrm{mg} / \mathrm{L} \text { every } 2 \text { days }\end{array}$ & 4 weeks & $\begin{array}{l}\text { PPAR } \gamma \mid \downarrow, \text { PPAR } \gamma 2 \downarrow \text {, Mest }{ }^{\mathrm{F}} \downarrow \\
\text { MCP-I }^{G} \downarrow, \text { IL- } 6 \downarrow, \text { ROS } \downarrow\end{array}$ & $\begin{array}{l}\text { Ameliorated metabolic } \\
\text { dysfunction; Inhibited adipocyte } \\
\text { differentiation }\end{array}$ & [97] \\
\hline $\begin{array}{l}\text { Gestational diabetes- } \\
\text { induced C57BL/KsJ } \\
+{ }^{+} \text {(wild type, } \\
\text { homozygous) and } \\
{\mathrm{C} 57 \mathrm{BL} / \mathrm{Ks}{ }^{\mathrm{db} /+}(\mathrm{db} /+} \\
\text { heterozygous) mice }\end{array}$ & $\begin{array}{l}\text { Protocol I: } 10, \\
20 \mathrm{mg} / \mathrm{kg} \text { b.w; } \\
\text { Protocol 2: } 20 \mathrm{mg} / \mathrm{kg} \\
\text { intragastric tube }\end{array}$ & 4 weeks & $\begin{array}{l}\text { TBARS } \downarrow, \text { SOD } \uparrow, \text { CAT } \uparrow, \\
\text { GSH } \uparrow, T C \downarrow, T G \downarrow, \text { LDL } \downarrow, \\
\text { SREBP-I } \downarrow \text {, FAS } \downarrow, \text { SCD-I }, \\
\text { ACC } \downarrow\end{array}$ & $\begin{array}{l}\text { Antioxidation and regulation of } \\
\text { oxidative stress; Inhibited the } \\
\text { mRNA induction of lipogenic } \\
\text { genes }\end{array}$ & [86] \\
\hline HCD Male SD rats & $0.1 \%, 0.5 \%$ diet orally & 6 weeks & $\begin{array}{l}\text { ALT } \downarrow, \text { AST } \downarrow, T C \downarrow, \text { HDL- } \\
\text { C } \uparrow, \mathrm{HDL} / \mathrm{TC} \uparrow, \mathrm{GSH}-\mathrm{Px} \uparrow, \\
\text { SOD } \uparrow, \text { TBARS } \downarrow\end{array}$ & $\begin{array}{l}\text { Liver protective effect; } \\
\text { Antioxidation and regulation of } \\
\text { oxidative stress; protection } \\
\text { against lymphocyte DNA } \\
\text { damage in both unstressed and } \\
\text { stressed cells; Inhibited } \\
\text { pancreatic lipase activity }\end{array}$ & [7I] \\
\hline
\end{tabular}


Table I (Continued).

\begin{tabular}{|c|c|c|c|c|c|}
\hline Model & Diosgenin Dose & Duration & $\begin{array}{l}\text { Effects on the Plasma } \\
\text { Lipid Profile and } \\
\text { Transcription Factors }\end{array}$ & Pharmacological Effect & Reference \\
\hline $\begin{array}{l}\text { HFD Male KK-Ay/Ta Jcl } \\
\text { mice (obese diabetic } \\
\text { model) }\end{array}$ & $\begin{array}{l}0.5 \%, 2.0 \% \text { fenugreek } \\
\text { orally }\end{array}$ & 4 weeks & $\begin{array}{l}\text { TG } \downarrow, \text { SREBP-I } \downarrow, \text { FAS } \downarrow \\
\text { SCD-I } \downarrow, A C C \downarrow, \text { LXR } \downarrow\end{array}$ & $\begin{array}{l}\text { Inhibited the mRNA induction } \\
\text { of lipogenic genes; Inhibited } \\
\text { hepatic steatosis }\end{array}$ & [53] \\
\hline $\begin{array}{l}\text { HFD KK-Ay/Ta Jcl mice } \\
\text { (obese diabetic model) }\end{array}$ & $\begin{array}{l}0.5 \%, 2 \% \text { fenugreek } \\
\text { orally }\end{array}$ & 4 weeks & $\begin{array}{l}\text { aP2 } \uparrow, \text { LPL } \uparrow, \text { Glut } 4 \uparrow, \\
\operatorname{PPAR} \gamma \mid \uparrow, \text { MCP-I } \downarrow \text {, TNF- } \\
\alpha \downarrow \text {, adiponectin } \uparrow\end{array}$ & $\begin{array}{l}\text { Enhanced insulin sensitivity; } \\
\text { Promoted adipocyte } \\
\text { differentiation and inhibited } \\
\text { obesity-related inflammation }\end{array}$ & [72] \\
\hline $\begin{array}{l}\text { HCD Male New } \\
\text { Zealand White rabbits }\end{array}$ & $\begin{array}{l}50 \mathrm{~g} / \mathrm{kg} 50 \text { mesh-size, } \\
50 \mathrm{~g} / \mathrm{kg} \text { nanoscale } \\
\text { Dioscorea } \\
\text { pseudojaponica } \\
\text { orally }\end{array}$ & 8 weeks & $\mathrm{TC} \downarrow, \mathrm{TG} \downarrow, \mathrm{AMPK} \uparrow, \mathrm{ACC} \uparrow$ & $\begin{array}{l}\text { Prevented lipid accumulation } \\
\text { within liver tissue; Accelerated } \\
\text { lipid catabolism }\end{array}$ & [54] \\
\hline $\begin{array}{l}\text { Semipurified-diet }+0.1 \% \\
\text { cholesterol female } \\
\text { cynomolgus macaques }\end{array}$ & I\% die orally & 3 weeks & $\mathrm{TC} \downarrow, \mathrm{TG} \downarrow$ & Increased cholesterol excretion & [38] \\
\hline Male apoE KO mice & $1 \%(w / w)$ orally & 8 weeks & $\begin{array}{l}\mathrm{TC} \downarrow, \mathrm{FC} \downarrow, \mathrm{CE} \downarrow, \mathrm{ABCA} I \uparrow \\
\text { miR-19b } \downarrow\end{array}$ & $\begin{array}{l}\text { Enhanced macrophage } \\
\text { cholesterol efflux; Inhibited } \\
\text { macrophage cholesterol } \\
\text { accumulation; accelerated RCT } \\
\text { and improves plasma lipid } \\
\text { profile; Inhibited aortic lipid } \\
\text { deposition and atherogenesis }\end{array}$ & [63] \\
\hline HFD Male SD rats & $\begin{array}{l}0.5 \%, 1 \%(w / w) \\
\text { orally }\end{array}$ & 16 weeks & $\begin{array}{l}\mathrm{HDL} \uparrow, \mathrm{LDL} \downarrow, \mathrm{TG} \downarrow, \mathrm{ALT} \downarrow \\
\mathrm{PAMPK} \uparrow, \mathrm{PACC} \uparrow, \mathrm{AMPK} \uparrow, \\
\mathrm{ACC} \uparrow, \mathrm{SREBPI}-\mathrm{-} \downarrow, \mathrm{LXR} \alpha \downarrow\end{array}$ & $\begin{array}{l}\text { Increased AMPK and ACC } \\
\text { phosphorylation; accelerated } \\
\text { lipid catabolism }\end{array}$ & [9I] \\
\hline $\begin{array}{l}45 \% \text { kcal-fat content } \\
\text { male Wistar rats }\end{array}$ & $\begin{array}{l}20,40,80 \mathrm{mg} / \mathrm{kg} \text { for } \\
\text { mice and } \mathrm{I5}, 30 \text {, } \\
60 \mathrm{mg} / \mathrm{kg} \text { for rats } \\
\text { orally }\end{array}$ & 8 weeks & 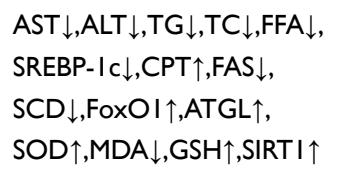 & $\begin{array}{l}\text { Improved hepatic lipid } \\
\text { metabolism; decreased } \\
\text { triacylglycerol accumulation }\end{array}$ & [87] \\
\hline $\begin{array}{l}\text { HepG2 cells; THP-I } \\
\text { monocytic cells }\end{array}$ & $\begin{array}{l}\text { Protodioscin, } \\
\text { pseudoprotodioscin, } \\
\text { methylprotodioscin } \\
(5 \mu \mathrm{m}, 10 \mu \mathrm{m}, 25 \mu \mathrm{m})\end{array}$ & $24 \mathrm{~h} ; 48 \mathrm{~h}$ & $\begin{array}{l}\text { ABCAI } \uparrow, \text { SREBP-I } \\
\text { SREBP- } 2 \downarrow, \text { LXR } \alpha \downarrow, P C S K 9 \downarrow, \\
\text { FAS } \downarrow, A C C \downarrow, \text { LDLR } \uparrow\end{array}$ & $\begin{array}{l}\text { Inhibited cholesterol } \\
\text { triglycerides synthesis; } \\
\text { accelerated RCT and improved } \\
\text { plasma lipid profile; }\end{array}$ & [64] \\
\hline $\begin{array}{l}\text { Human THP-I } \\
\text { monocytic cells; HepG2 } \\
\text { cells }\end{array}$ & $\begin{array}{l}\text { Methyl protodioscin } \\
(100 \mu \mathrm{m})\end{array}$ & $24 \mathrm{~h}$ & $\begin{array}{l}\text { SREBPI } \downarrow \text {,SREBP } 2 \downarrow, \mathrm{miR}- \\
33 \mathrm{a} / \mathrm{b} \downarrow, \mathrm{ABCA} \mid \uparrow, \mathrm{HMGCR} \uparrow, \\
\text { FAS } \downarrow, A C C \downarrow, L X R \alpha \downarrow\end{array}$ & $\begin{array}{l}\text { Inhibited cholesterol } \\
\text { triglycerides synthesis }\end{array}$ & [45] \\
\hline $\begin{array}{l}\text { C57BL/6 male mice; } \\
\text { Wistar male rats }\end{array}$ & $\begin{array}{l}\text { Acute experiment: } \\
28,56,84 \mathrm{mg} / \mathrm{kg} / \mathrm{d} \text {; } \\
\text { chronic test: } 20,40 \text {, } \\
60 \mathrm{mg} / \mathrm{kg} / \mathrm{d} \text {; } \\
\text { intragastrically }\end{array}$ & $\begin{array}{l}\text { Acute } \\
\text { experiment: } \\
2 \text { weeks; } \\
\text { chronic test: } \\
12 \text { weeks }\end{array}$ & $\begin{array}{l}\mathrm{AST} \downarrow, \mathrm{ALT} \downarrow, \mathrm{TG} \downarrow, \mathrm{TC} \downarrow \\
\mathrm{SOD} \uparrow, \mathrm{MDA} \downarrow, \mathrm{GSH} \uparrow, \mathrm{GSH}- \\
\mathrm{Px} \uparrow, \mathrm{GSR} \uparrow, \mathrm{TnF}-\alpha \downarrow, \mathrm{IL}-6 \downarrow, \\
\mathrm{P} 38 \downarrow, \mathrm{PERK} \downarrow, \mathrm{PJNK} \downarrow, \\
\text { CYP2EI } \downarrow, \mathrm{PPAR} \alpha \uparrow, \mathrm{CPT} \uparrow, \\
\text { MCAD } \uparrow\end{array}$ & $\begin{array}{l}\text { Reduced the oxidative stress, } \\
\text { Inflammatory cytokine } \\
\text { production, apoptosis and liver } \\
\text { steatosis }\end{array}$ & [70] \\
\hline
\end{tabular}

(Continued) 
Table I (Continued).

\begin{tabular}{|c|c|c|c|c|c|}
\hline Model & Diosgenin Dose & Duration & $\begin{array}{l}\text { Effects on the Plasma } \\
\text { Lipid Profile and } \\
\text { Transcription Factors }\end{array}$ & Pharmacological Effect & Reference \\
\hline $\begin{array}{l}\text { HFD C57BL/6] male } \\
\text { mice }\end{array}$ & $\begin{array}{l}50,100 \text { dioscin mg/ } \\
\mathrm{kg} / \mathrm{d} \text { intragastrically }\end{array}$ & 7 weeks & $\begin{array}{l}\text { SREBP- Ic } \downarrow \text {, FAS } \downarrow, \text { GLUT4 } \downarrow \text {, } \\
\text { PAMPK } \uparrow, \text { pACC } \uparrow, p 38 \downarrow, \\
\text { pERK } \downarrow\end{array}$ & $\begin{array}{l}\text { Inhibited cholesterol } \\
\text { triglycerides synthesis; } \\
\text { Increased AMPK and ACC } \\
\text { phosphorylation; }\end{array}$ & [57] \\
\hline SW480 cell & $6.21 \mu \mathrm{g} / \mathrm{mL}$ & $24 \mathrm{~h} ; 48 \mathrm{~h}$ & $\begin{array}{l}\text { ACC } \downarrow, F A S \downarrow, P P A R \gamma \uparrow, \\
\operatorname{LDLR} \uparrow\end{array}$ & $\begin{array}{l}\text { Inhibited the mRNA induction } \\
\text { of lipogenic genes; decreased } \\
\text { cholesterol absorption }\end{array}$ & [88] \\
\hline \multirow[t]{2}{*}{ HFD Male SD rats } & $\begin{array}{l}150,300 \mathrm{mg} / \mathrm{kg} / \mathrm{d} \text {, } \\
\text { intragastrically }\end{array}$ & 8 weeks & $\begin{array}{l}\text { TC } \downarrow, T G \downarrow, \text { LDL-C } \downarrow, \text { HDL- } \\
\mathrm{C} \uparrow, \mathrm{SRB} \mid \uparrow, \mathrm{CES}-\mathrm{I} \uparrow, \\
\mathrm{CYP7AI} \uparrow, \mathrm{FXR} \downarrow\end{array}$ & $\begin{array}{l}\text { Accelerated hepatic RCT; } \\
\text { enhanced cholesterol } \\
\text { elimination }\end{array}$ & [49] \\
\hline & $1 \%(\lg / 100 g)$ & & & & \\
\hline
\end{tabular}

Abbreviations: ${ }^{{ }^{H} H F D}$, High-fat diet-fed; ${ }^{\mathrm{B} S D}$, Sprague-Dawley; ${ }^{\mathrm{C} S P F}$, specific-pathogen-free; ${ }^{\mathrm{D}} \mathrm{HCD}$, high-cholesterol diet; ${ }^{\mathrm{E}} \mathrm{STZ}$, Streptozotocin-Induced; ${ }^{\mathrm{F}}$ Mest, mesoderm specific transcript; ${ }^{G} \mathrm{MCP}-\mathrm{I}$, monocyte chemoattractant protein.

the intestine. When diosgenin and cholesterol are both present, diosgenin competes for bile acid binding to inhibit cholesterol absorption. ${ }^{41}$ Overall, these results indicate that diosgenin can inhibit lipid absorption by downregulating NPC1L1 expression and competing with cholesterol for bile acids in the intestinal tract.

\section{Regulation of Cholesterol Transport}

In addition to blood cholesterol and triglycerides, lipoproteins, such as HDL and LDL, also have important roles in lipid metabolism, as they function to transport lipids and cholesterol that are generally insoluble in blood. Kuang et $\mathrm{al}^{42}$ applied diosgenin to the lipogenic normal human liver (L02) cell model, and the results showed that diosgenin could up-regulate expression of Caveolin-1 protein, which is closely related to cholesterol transport, and reduce intracellular cholesterol levels. Protodioscin has potent HDL and LDL (especially LDL) lowering effects. ${ }^{37}$ Numerous studies have shown that HDL-C concentration is inversely correlated with CVD risk; hence, raising plasma HDL-C levels may protect against CVD. ${ }^{43}$ In rats fed a high-cholesterol diet (HCD), supplementation with $0.5 / 100 \mathrm{~g}$ diosgenin for 4 weeks led to a slight increase in serum HDL-C and fecal bile acid levels, and a decrease in lipid droplet size. ${ }^{44}$ Sterol regulatory element-binding proteins (SREBPs) regulate the balance of LDL, HDL, and triglyceride levels in vivo. In human THP-1 macrophages, methyl protodioscin (MPD) inhibits $S R E B P 1 C$ and SREBP2 transcription and decreases levels of microRNA 33a/b, which is encoded in SREBP gene introns, leading to a corresponding increase in ATP binding cassette A1 (ABCA1) levels. ${ }^{45}$ Since ABCA1 is a key protein in HDL biogenesis, low miR-33a/b levels result in high HDL-C. Further, MPD also decreases expression of the 3-hydroxy-3-methylglutaryl-coenzyme A (HMG-CoA) reductase $(H M G C R)$, fatty acid synthase $(F A S)$, and acylCoA carboxylase $(A C C)$ genes, which are involved in cholesterol and fatty acid synthesis. Therefore, MPD may increase HDL-C levels, and decrease LDL-C and triglyceride levels.

Scavenger receptor class B type I (SRB1) is a receptor physiologically related to HDL, which participates in reverse transport of cholesterol (RCT) and helps to transport excess cholesterol to the liver in the form of cholesterol ester (CE), and then excrete it into bile and feces. ${ }^{46}$ Carboxylesterase 1 (CES-1) exhibits cholesteryl ester hydrolase activity, and contributes to hydrolyzation of HDL-CE to free cholesterol (FC), which is available for bile acid synthesis. ${ }^{47}$ Cholesterol $7 \alpha$-hydroxylase (CYP7A1) is the initial and rate-limiting enzyme in the classical BA synthetic pathway, which regulates the total rate of BA generation. Farnesol $\mathrm{X}$ receptor (FXR) is a nuclear receptor with fundamental roles in maintaining $\mathrm{BA}$ homeostasis and in maintaining the balance between cholesterol and BA. BAs, specifically hydrophobic BAs, act as ligands for FXR and utilize it in their negative feedback loop. ${ }^{48}$ In an in vivo experiment, Yu et $\mathrm{al}^{49}$ demonstrated that diosgenin $(150$ or $300 \mathrm{mg} / \mathrm{kg} / \mathrm{d}$ ) can 
reduce body weight and blood lipid levels of rats fed a HFD, and significantly improve liver steatosis and intestinal structure. Further, diosgenin can increase the expression of SRB1, CES-1, and CYP7A1 in rat liver and inhibit FXR-mediated signal transduction, as well as increasing SRB1 and CES-1 expression in rat intestine, inhibiting cholesterol absorption, and promoting RCT. Hence, diosgenin promotes RCT and cholesterol clearance through the SRB1/CES-1/CYP7A1/FXR pathway, which suggests potential new approaches to alleviate hypercholesterolemia. Together, the results above indicate that diosgenin can increase HDL-C and decrease LDL-C and very lowdensity lipoprotein (VLDL) cholesterol (VLDL-C) levels by regulating cholesterol transport, and thus participate in regulating blood lipid levels.

\section{Inhibiting Endogenous Lipid Biosynthesis}

HMGCR is an endoplasmic reticulum bound peroxisome enzyme that catalyzes the reduction of HMG-CoA to COA and mevalonate, which is a rate-limiting reaction in the de novo cholesterol biosynthesis pathway; it is highly expressed in the liver and plays a central role in the regulation of cholesterol metabolism. ${ }^{50}$ It is established that HMGCR inhibitors can effectively reduce plasma cholesterol levels in most animals, including humans and these inhibitors are widely used as statins to reduce cholesterol levels by inhibiting cholesterol synthesis. ${ }^{51}$ Hao et al showed that oral administration of diosgenin $(40 \mathrm{mg} /$ $\mathrm{kg}$ orally for 45 days) could significantly reduce mRNA levels encoding HMGCR in the liver of diabetic rats, suggesting that diosgenin can significantly reduce cholesterol synthesis. ${ }^{52}$ Diosgenin may inhibit cholesterol biosynthesis by blocking the substrate from entering the active site of the HMGCR enzyme. Uemura et al reported that diosgenin (5 and $10 \mathrm{mmol} / \mathrm{l})$ decreased triglyceride content and mRNA expression levels of genes involved in lipid synthesis (FAS, stearoyl-CoA desaturase 1 ( $S C D-1)$, and $A C C$ ) by inhibiting SREBP-1c mRNA expression, resulting in inhibited lipid accumulation in hepatocellular carcinoma (HepG2) cells. ${ }^{53}$ A study to investigate the lipid-lowering effects of different granule treatments (50 $\mathrm{g} / \mathrm{kg} 50$ mesh-size flour or $50 \mathrm{~g} / \mathrm{kg}$ nanoscale flour) showed that both Dioscorea pseudojaponica particle types could activate adenosine 5'-monophosphateactivated protein kinase (AMPK) and inactivate ACC, as demonstrated by increased levels of phosphorylated enzyme. ${ }^{54}$ AMPK activation increases the rate of the catabolic (ATP production) pathway and reduces the rate of the anabolic (ATP utilization) pathway. ${ }^{55}$ Cheng hypothesized that diosgenin can stimulate AMPK activation, promote free fatty acid (FFA) decomposition and, under the synergistic effect of liver X receptor alpha (LXR $\alpha$ ), inhibit SREBPIC and reduce triglyceride synthesis. ${ }^{56}$ Poudel et al demonstrated that diosgenin targets the AMPK/MAPK pathway, suppresses mitotic clonal expansion during the early phase of adipogenesis, and decreases the expression of adipogenic transcription factors in 3T3-L1 cells during adipogenesis. At a dose of $4 \mu \mathrm{M}$, diosgenin inhibited lipid accumulation in 3T3-L1 cells, but did not affect cell viability. Further, diosgenin can also regulate weight and fat accumulation induced by HFD in obese mice. ${ }^{57}$ In summary, diosgenin inhibits one or several links in the cholesterol and triglyceride biosynthetic pathways, thereby reducing cholesterol and triglyceride levels.

\section{Promoting Conversion of Cholesterol into Bile Acid and Excretion}

The classical route for the human body to remove cholesterol lipid is via promotion of cholesterol excretion into biliary cholesterol, the conversion of cholesterol into bile acid, and its subsequent fecal excretion. ${ }^{58,59}$ The ATPbinding cassette $(\mathrm{ABC})$ transporters, G5 (ABCG5) and G8 (ABCG8), are hemi-transporters, which play an important role in preventing the accumulation of dietary sterols (including cholesterol and phytosterols) in the body. ${ }^{60} \mathrm{Li}$ et al reported that, after treatment with 0.15 or $0.3 \mathrm{~g} / \mathrm{kg}$ diosgenin, ABCG5/G8 expression was increased in the liver and intestine of HFD rats, suggesting that it can promote bile cholesterol secretion. ${ }^{21}$ Temel et al ${ }^{61}$ showed that fecal excretion of neutral sterols (cholesterol and its bacterial metabolites) in wild-type mice fed with $0.1 \%$ diosgenin increased from 4.2 to $52 \mu \mathrm{mol} /$ day/100 g body weight. Compared with wild-type mice receiving a control diet, the fecal neutral sterol excretion of NPC1L1 knockout mice was also significantly increased, from 63 to 140 $\mu \mathrm{mol} / \mathrm{day} / 100 \mathrm{~g}$ body weight. This study demonstrated that diosgenin promotes fecal cholesterol excretion independently of NPC1L1-mediated cholesterol absorption, and that diosgenin may facilitate fecal cholesterol loss to a greater extent in NPC1L1 knockout mice than in wildtype mice.

ABCA1 mediates the transfer of cellular phospholipids (PL) and FC to apolipoprotein A-I (ApoA-I) and related proteins in extracellular medium, acting as a lipid transporter. ${ }^{62}$ Diosgenin can promote ABCA1 expression 
in macrophages by inhibiting miR-19b levels, and accelerate macrophage cholesterol efflux through the ABCA1 pathway and RCT process. $^{63}$ In HepG2 cells, $25 \mu \mathrm{m}$ pseudoprotodioscin (PPD), a steroidal saponin similar to diosgenin, significantly increased levels of ABCA1 protein and mRNA, and promoted ApoA-1 mediated cholesterol excretion. The underlying mechanism involves PPD inhibition of SREBP1C and SREBP2 transcription by reducing microRNA33a/b levels, leading to increased ABCA1. ${ }^{64}$ In summary, diosgenin can promote the conversion of cholesterol to bile acid and increase its excretion in various ways; however, details of the complex molecular mechanisms involved remain to be clarified.

\section{Oxidative Stress and Anti-Oxidant Properties}

Oxidation-reduction equilibrium is essential to maintain the normal operation of vital cell functions. Oxidative stress is common in some diseases, including cancer, CVD, atherosclerosis, and diabetes. ${ }^{65}$ Endogenous markers of oxidative stress include superoxide dismutase (SOD), glutathione peroxidase (GPx), and reduced glutathione (GSH). During oxidative stress, phospholipids in cell membranes are oxidized by thiobarbituric acid reactive substances (TBARS), which hinder their biological functions. Diosgenin has potent in vitro anti-oxidative and in vivo anti-inflammatory activities ${ }^{66}$ and participates in glucose metabolism, reduces oxidative stress, increases cell viability, and decreases reactive oxygen species levels. ${ }^{67}$ Sangeetha et al $^{68}$ assessed the antioxidant status of experimental rat liver and heart tissue samples treated with and without diosgenin. The rats were fed with an HFD for 8 weeks and then received streptozotocin (STZ) injection to induce a type 2 diabetes model. GSH levels were higher in animals treated with diosgenin $(40 \mathrm{mg} / \mathrm{kg}$, $80 \mathrm{mg} / \mathrm{kg}$ ), although they did not reach the range of those in normal rats. Diosgenin can also maintain SOD and GPX activities and control TBARS production. Rats with chronic renal failure (CRF) were administered diosgenin orally (40 $\mathrm{mg} / \mathrm{kg} / \mathrm{day})$, and subsequent results demonstrated that diosgenin increased GSH levels and restored endothelial nitric oxide synthase (eNOS) mRNA expression. Further, diosgenin inhibits dyslipidemia and angiotensin converting enzyme (ACE) activity caused by CRF. Overall, data published to date show that diosgenin has potential to protect blood vessels from oxidative stress and dyslipidemia. ${ }^{69} \mathrm{Xu}$ et $\mathrm{al}^{70}$ found that dioscin significantly attenuated the increase in malondialdehyde levels caused by ethanol and significantly elevated SOD, GSH, GSH-Px, and GSR levels. These data indicate that dioscin has an excellent protective effect against ethanolinduced liver injury by reducing oxidative stress, inflammatory cytokine production, apoptosis, and liver steatosis. Further, diosgenin acts as an antioxidant in cell membranes, which may provide protection against oxidative damage of polyunsaturated fatty acids. ${ }^{71}$ Fenugreek, which contains diosgenin, can improve glucose metabolism disorder caused by HFD by promoting adipocyte differentiation, inhibiting inflammation of white adipose tissue, and miniaturizing adipocytes. ${ }^{72}$ Numerous studies have demonstrated that diosgenin can regulate blood lipids by removing excessive free radicals and reducing physiological lipid deposition.

\section{Regulating Lipase Activity}

Hepatic lipoprotein lipase (LPL) and hepatic lipase (HL) are important in the process of lipoprotein hydrolysis. Once lipoproteins are transported to the circulation, specific lipases can help to release their lipid components. The secretory dimer lipases, LPL and HL, hydrolyze triglycerides in lipoproteins and provide FFA for tissues. LPL is secreted from the parenchyma of adipose and muscle to the capillary lumen and acts on VLDL and chylous particles. HL is secreted by hepatocytes and acts on residual lipoprotein and HDL rich in cholesterol. ${ }^{73}$ Diosgenin increases LPL and HL activity in a dose-dependent manner. Compared with an HFD rat model group, rats treated with diosgenin $(132.8 \mathrm{mg} / \mathrm{kg})$ had significantly increased activities of LPL and HL. ${ }^{74}$

Pancreatic lipase (PL) is a dietary lipid digestive enzyme, inhibition of which reduces triglyceride digestion and lipid absorption. ${ }^{75}$ Kwon et al $^{76}$ demonstrated that dioscin and diosgenin have strong inhibitory effects on PL activity. After treatment with dioscin $(100 \mathrm{mg} / \mathrm{kg})$ or diosgenin $(100 \mathrm{mg} / \mathrm{kg})$, the elevation of plasma triacylglycerol concentration was significantly reduced in mice orally injected with corn oil. Further, in an 8-week experiment, rats fed with a HFD containing $2 \%$ or $5 \%$ Dioscorea nipponica powder exhibited significantly suppressed weight gain and prevented dietary fat absorption relative to controls fed the HFD alone. The cholesterol-lowering effect of saponins and sapogenins has been widely described in literature regarding the treatment of hyperlipidemia. Navarro Del Hierro et $\mathrm{al}^{77}$ found that saponinrich extracts and their hydrolysates from fenugreek and 
quinoa can inhibit PL activity. Although the exact role of sapogenins contained in the hydrolyzed extracts in lipase inhibition remains unclear, the study provided a potential baseline for the development of multi-bioactive products that act against pancreatic lipase and cholesterol absorption simultaneously. In summary, diosgenin reduced dietary fat decomposition and absorption in the digestive organs by reducing the hydrolytic activity of these key enzymes, thus alleviating the symptoms of metabolic diseases, such as hyperlipidemia. In future, the regulation of lipase activity by diosgenin warrants further research.

\section{Regulating Transcription Factors Related to Lipid Metabolism}

The metabolic enzymes and receptors involved in lipid metabolism are regulated by various transcription factors. Molecules established as involved in lipid metabolism include SREBPs, ${ }^{78,79} \mathrm{LXRs}^{80,81}$ and peroxisome proliferator activated receptors (PPAR). ${ }^{82,83}$

SREBPs directly activate the expression of more than 30 genes, which contribute to the synthesis and uptake of cholesterol, fatty acids, triglycerides, and phospholipids, as well as nicotinamide adenine dinucleotide phosphate cofactors required for the synthesis of these molecules. ${ }^{84}$ SREBP-1c preferentially enhances the transcription of genes required for fatty acid synthesis, which is a key regulator of lipid synthesis and accumulation. ${ }^{85}$ Diosgenin can inhibit the increased expression of the sterol regulatory element-binding protein, SREBP-1, and that of its target genes, including $F A S, S C D-1$, and $A C C .^{86}$ Mechanistic studies demonstrated that dioscin can regulate the expression levels of downstream proteins, including SREBP-1c, carnitine palmitoyl transferase, FAS, SCD, forkhead box O1, and adipose triglyceride lipase, by regulating the Silent information regulator of transcription 1 (SIRT1)/AMPK signaling pathway, thus significantly reducing lipid metabolism. ${ }^{87}$ One study reported significant down-regulation of $A C C$ and $F A S$, alongside upregulation of PPAR $\gamma$ and LDL receptor $(L D L R)$, genes at the mRNA level in SW480 cell lines treated with $6.21 \mu \mathrm{g} /$ $\mathrm{mL}$ diosgenin. ${ }^{88}$ These findings indicate that SREBP is a key hub in diosgenin regulation of abnormal lipid metabolism.

LXRs, particularly liver LXR $\alpha$, have important roles in the transcriptional regulation of lipid metabolism. As a cholesterol sensor, the nuclear receptor, LXR, is a crucial factor in regulating cholesterol homeostasis.
LXR $\alpha$ activation can promote the RCT process, cholesterol catabolism, and cholesterol excretion. ${ }^{81}$ By contrast, LXR agonists increase hepatic and plasma levels of triglyceride in mice, owing to enhanced fatty acid biosynthesis and VLDL secretion. ${ }^{89}$ Activated LXRs can promote cholesterol metabolism; however, they inevitably produce classical lipogenic side effects. SREBP1 is a significant target of LXR $\alpha$ in upregulating lipogenesis, LXR enhances fatty acid synthesis by activating SREBPIc transcription, which in turn transactivates lipogenic genes. LXR also directly stimulates the transcription of specific lipogenic genes, including acetyl-CoA carboxylase $\alpha(A C A C A)$ in chick embryos and fatty acid synthase (FASN) in human cells. ${ }^{90}$ Diosgenin $(10,25$, and $50 \mu \mathrm{M})$ significantly inhibited the accumulation of TG and the increase of SREBP- $1 c$ mRNA in HepG2 cells induced by high glucose levels. In addition, compared with the model group, diosgenin $(0.5 \%$ or $1 \% \mathrm{w} / \mathrm{w})$ treated rats fed with a HFD also exhibited significantly suppressed LXR $\alpha$ levels. ${ }^{91}$ These data demonstrate that diosgenin may influence fatty acid metabolism by regulating the LXR $\alpha /$ SREBP-1c signaling pathway. To date, there has been insufficient study of whether diosgenin can regulate cholesterol metabolism-related pathways through LXRs to maintain cholesterol homeostasis. It will be of great significance to further ascertain the specific mechanism underlying diosgenin-mediated regulation of LXRs.

PPARs are members of the nuclear receptor superfamily, and their physiological functions are related to metabolism, energy homeostasis, and cell development and differentiation. Three PPARs have been identified: PPAR $\alpha$, PPAR $\gamma$, and PPAR $\beta / \delta .^{92}$ Many PPAR agonists have been synthesized to treat metabolic diseases, particularly dyslipidemia and type 2 diabetes mellitus (T2DM), due to their crucial metabolic regulatory roles and excellent druggability. ${ }^{93}$ Hepatic PPAR $\alpha$ stimulates fatty acid catabolism by modulating the expression of LPL, apolipoprotein genes, fatty acid transport and oxidation genes, and genes involved in HDL metabolism and ketone synthesis. Therefore, PPAR $\alpha$ activators have vital roles dyslipidemia treatment. ${ }^{94}$ Sangeetha et $\mathrm{al}^{68}$ detected a slight increase in PPAR $\alpha$ expression in 3T3-L1 cells treated with diosgenin at $0.5,1$, and $10 \mu \mathrm{M}$, but the increase was not as significant as that of PPAR $\gamma$. PPAR $\gamma$ is mainly expressed in adipose tissue, hematopoietic cells, and the large intestine, and has key roles in lipid and glucose metabolism. ${ }^{95}$ PPAR $\gamma$ agonists are widely used for T2DM treatment and their clinical efficacy as oral antidiabetic agents is well 
established; ${ }^{96}$ however, there is controversy about the effect of diosgenin on PPAR $\gamma$, one study showed that diosgenin can down-regulate PPAR $\gamma$ expression and activity, and inhibit adipocyte differentiation. ${ }^{97}$ Another study showed that diosgenin is a selective agonist of PPAR $\gamma$ and up-regulates its expression. This may be why adipogenesis was observed in 3T3-L1 cells, resulting in reduced circulating free lipids in diabetic animals, and diosgenin may be considered as a hypolipidemic drug. ${ }^{68}$ At present, the mechanism underlying of the effects of diosgenin on PPARs are unclear. In silico docking studies showed that PPAR $\alpha$ and PPAR $\gamma$ both interact with diosgenin, while the efficiency of diosgenin binding to PPAR $\gamma$ is higher than that of PPAR $\alpha{ }^{68}$ This raises a question of whether diosgenin may be a dual agonist of both PPAR $\alpha$ and PPAR $\gamma$. A recent study showed that integrative application of PPAR $\alpha$ and PPAR $\gamma$ agonists may decrease hepatic lipid accumulation, oxidative stress, and production of inflammatory cytokines, which may be due to the synergistic effect of PPAR $\alpha$ and PPAR $\gamma$ in regulating the expression of the downstream target genes, SREBP-1c, FAS, DGAT, $L P L$, and $N F-j B .^{98}$ As synthetic ligands have many side effects, ${ }^{99}$ using natural agonists, such as diosgenin, may be a safe alternative method for targeted regulation of lipid metabolism. Diosgenin can also be considered a dual agonist, which could provide a better balance between efficacy and side effects, compared with single agonists or dual agonists with varying potency.

In summary, diosgenin participates in regulating lipid metabolism through multiple targets and pathways. The underlying mechanisms are highly complex and more animal studies and clinical trials are needed to unravel the details in the future.

\section{Advantages and Limitations of Diosgenin}

Plant extracts and their derivatives are widely used to treat various diseases because of their high bioavailability, low side effects, and low cost. In recent years, diosgenin and its derivatives have been the focus of considerable research efforts worldwide. Numerous studies have elucidated the pharmacological effects of diosgenin and its derivatives on various diseases, such as cancer, ${ }^{23}$ diabetes, ${ }^{100}$ and osteoporosis. ${ }^{101}$ Diosgenin can be obtained from various medicinal plants, particularly fenugreek seeds, which represent a comprehensive and lowcost source. In general, diosgenin and other plant-derived compounds have lower toxicity than chemical drugs. Notably, diosgenin has good cytotoxic activity toward HepG2 cells, but relatively low toxicity to L02 cells, indicating a degree of selectivity between normal and tumor cells. ${ }^{102}$ We infer that steroidal saponins, including diosgenin, do not show any significant toxicity at conventional dosages. Due to the poor water solubility and strong hydrophobicity of diosgenin, its oral bioavailability is not ideal, and numerous diosgenin formulation strategies have been applied to overcome these issues, including liquid crystalline (LCs) and b-cyclodextrin (b-CD) complexes, nanocrystals, and soluplus-mediated diosgenin Amorphous Solid Dispersion (ASD) technology. ${ }^{103,104}$ In recent decades, ASDs have been the subject of increased research interest, as they can increase the oral bioavailability of poorly soluble drugs. ${ }^{105}$ The aqueous solubility of optimized ASDs was significantly improved due to the amorphization of diosgenin and the molecular interactions between diosgenin and soluplus. Furthermore, pharmacokinetic studies in rats revealed that the bioavailability of diosgenin from ASDs was improved approximately fivefold. Hence, diosgenin ASDs, with their high solubility, high bioavailability, and high stability, represent a promising route toward pharmaceutical applications. ${ }^{104}$ Simultaneously, although numerous preclinical studies have demonstrated that diosgenin has reliable lipid metabolism regulation function, clinical research data remain limited. Therefore, it will be necessary to verify the therapeutic effects of diosgenin on human hyperlipidemia via additional clinical trials in the future.

\section{Conclusion and Future Prospects}

Phytochemicals found in medicinal or edible plants have remarkable biological activity, high safety, low or no toxicity, and represent alternative resources for developing new drugs. Diosgenin is a natural steroidal saponin, with potential for broad application. Numerous studies have confirmed the great potential for use of diosgenin in the treatment and prevention of hyperlipidemia. In this paper, we reviewed the pharmacological mechanism underlying the effects of diosgenin in the treatment of hyperlipidemia, including its roles in inhibition of intestinal lipid absorption, regulation of cholesterol transport, promotion of cholesterol conversion into bile acid and excretion, inhibition of endogenous lipid biosynthesis, effects on antioxidation and lipoprotein lipase activity, and regulation of transcription factors related to lipid metabolism. Combined with research progress regarding 
the pathological mechanism underlying dyslipidemia, related pathways were discussed. Drugs to treat dyslipidemia mainly reduce blood lipids by regulating the kinetics of different parts of the metabolic cycle. Researchers worldwide are using network pharmacology, ${ }^{106}$ chromatography, mass spectrometry, ${ }^{107}$ and GCMS ${ }^{108}$ to study the pathogenesis and treatment of hyperlipidemia and the resulting findings will provide a scientific basis for understanding the "multi componentmulti target-multi pathway" mechanisms underlying the effects of diosgenin on hyperlipidemia.

In addition, several new diosgenin delivery systems have been developed by combining diosgenin with b-CD, LC, nanocrystalline, and ADS technologies, to improve the water solubility and bioavailability of the compound, which has been beneficial to the clinical application and biological activity of diosgenin. Drugs containing diosgenin are already marketed in China; however, there have been few reports on clinical trials of diosgenin for treating dyslipidemia, making it is difficult to assess the potential clinical benefits of diosgenin for treating human hyperlipidemia. Thus, more clinical trials are needed to ensure the effectiveness and safety of diosgenin when used to regulate human lipid metabolism. Diosgenin could be used as a small molecule probe to search for natural-binding partners in vivo that play important roles in reducing blood lipids. In the future, with further study on the mechanisms underlying diosgenin activity, diosgenin can be expected to play a safer and more effective pharmacological role and be appropriately applied in the treatment of disease in the clinic.

\section{Abbreviations}

CHD, coronary heart disease; VLDL-C, very lowdensity lipoprotein cholesterol; LDL-C, low-density lipoprotein cholesterol; HDL-C, high-density lipoprotein cholesterol; CVD, cardiovascular disease; CV, cardiovascular; VLDL, very low-density lipoprotein; LDL, low-density lipoprotein; LDLR, low-density lipoprotein receptor; IDL, medium-density lipoprotein; HDL, highdensity lipoprotein; SD, Sprague-Dawley; HFD, highfat diet; HCD, high-cholesterol diet; NPC1L1, Niemann-Pick C1-Like 1; SREBPs, Sterol regulatory element-binding proteins; SREBP-1, sterol regulatory element-binding protein; SREBP-2, sterol regulatory element-binding protein-2; MPD, methyl protodioscin; ABCA1, ATP binding cassette A1; HMG-CoA, 3-hydroxy-3-methylglutaryl-coenzyme A; HMGCR, 3-hydroxy-3-methylglutaryl-coenzyme A reductase;
FAS, fatty acid synthase; ACC, acyl-CoA carboxylase; SRB1, scavenger receptor class B type I; RCT, reverse transport of cholesterol; CE, cholesterol ester; CES-1, carboxylesterase 1; FC, free cholesterol; CYP7A1, cholesterol $7 \alpha$-hydroxylase; BA, bile acid; FXR, farnesol $\mathrm{X}$ receptor; FAS, fatty acid synthase; SCD-1, stearoylCoA desaturase 1; ACC, acetyl-CoA carboxylase; HepG2, hepatocellular carcinoma; AMPK, adenosine 5 -'monophosphate-activated protein kinase; FFA, free fatty acids; LXR, liver $X$ receptor; $L X R \alpha$, liver $\mathrm{X}$ receptor alpha; ABCG5, ATP-binding cassette transporters G5; ABCG5, ATP-binding cassette transporters G8; PL, phospholipids; ApoA-I, apolipoprotein A-I; PPD, pseudoprotodioscin; SOD, superoxide dismutase; GPx, glutathione peroxidase; GSH, glutathione; TBARS, thiobarbituric acid reactive substances; ROS, reactive oxygen species; STZ, streptozotocin-Induced; CRF, chronic renal failure; eNOS, endothelial nitric oxide synthase; ACE, angiotensin converting enzyme; MDA, malondialdehyde; LPL, lipoprotein lipase; HL, hepatic lipase; PL, pancreatic lipase; PPAR, peroxisome proliferator activated receptors; NADPH, nicotinamide adenine dinucleotide phosphate; SIRT1, silent information regulator of transcription 1; ACACA, acetyl-CoA carboxylase $\alpha$; FASN, fatty acid synthase; T2DM, type 2 diabetes mellitus; L02, normal human liver cells; LCs, liquid crystalline; b-CD, b-cyclodextrin; ASD, amorphous solid dispersion; SPF, specificpathogen-free; Mest, mesoderm specific transcript; MCP-1, monocyte chemoattractant protein; CM, chylomicron; PCSK9, proprotein convertase subtilisin/kexin type 9.

\section{Acknowledgments}

We want to thank Liping Zhang for her timely help in revising the grammar and logic of the manuscript. This paper was supported by the National Natural Science Foundation of China (No. 81573945), the Science and Technology Development Project of Shandong Province (No. 2013GSF11902), the National Prestigious Chinese Medicine Doctor Studio of Xinlu Wang Project ([2016]47), and the Science and Technology Development Project of Traditional Chinese Medicine in Shandong Province (Nos. 2013-081 and 2019-0093).

\section{Disclosure}

The authors report no conflicts of interest in this work. 


\section{References}

1. Karr S. Epidemiology and management of hyperlipidemia. Am J Manag Care. 2017;23(9 Suppl):S139-S148.

2. Benjamin EJ, Virani SS, Callaway $\mathrm{CW}$, et al. Heart disease and stroke statistics-2018 update: a report from the American heart association. Circulation. 2018;137(12):e67-e492.

3. Townsend N, Nichols M, Scarborough P, Rayner M. Cardiovascular disease in Europe-epidemiological update 2015. Eur Heart J. 2015;36(40):2696-2705. doi:10.1093/eurheartj/ehv428

4. Wang XG, Zhao X, Li Y, et al. Research progress of pathogenesis and treatment of hyperlipidemia. J Liaoning Univ Trad Chin Med. 2020;22(12):196-200.

5. Kopin L, Lowenstein C. Dyslipidemia. Ann Intern Med. 2017;167 (11):ITC81-ITC96. doi:10.7326/AITC201712050

6. Holven KB, Ulven SM, Bogsrud MP. Hyperlipidemia and cardiovascular disease with focus on familial hypercholesterolemia. Curr Opin Lipidol. 2017;28(5):445-447. doi:10.1097/ MOL.0000000000000449

7. Strilchuk L, Fogacci F, Cicero AF. Safety and tolerability of injectable lipid-lowering drugs: an update of clinical data. Expert Opin Drug Saf. 2019;18(7):611-621. doi:10.1080/ 14740338.2019.1620730

8. Stroes ES, Thompson PD, Corsini A, et al. Statin-associated muscle symptoms: impact on statin therapy-European Atherosclerosis Society consensus panel statement on assessment, aetiology and management. Eur Heart J. 2015;36(17):1012-1022. doi:10.1093/eurheartj/ehv043

9. Mach F, Baigent C, Catapano AL, et al. 2019 ESC/EAS guidelines for the management of dyslipidaemias: lipid modification to reduce cardiovascular risk. Eur Heart J. 2020;41(1):111-188.

10. Thomford NE, Senthebane DA, Rowe A, et al. Natural products for drug discovery in the 21st century: innovations for novel drug discovery. Int $J$ Mol Sci. 2018;19(6):1578. doi:10.3390/ ijms 19061578

11. Talebi S, Bagherniya M, Atkin SL, Askari G, Orafai HM, Sahebkar A. The beneficial effects of nutraceuticals and natural products on small dense LDL levels, LDL particle number and LDL particle size: a clinical review. Lipids Health Dis. 2020;19 (1):66. doi:10.1186/s12944-020-01250-6

12. Atanasov AG, Waltenberger B, Pferschy-Wenzig EM, et al. Discovery and resupply of pharmacologically active plant-derived natural products: a review. Biotechnol Adv. 2015;33(8):1582-1614.

13. Rodrigues T, Reker D, Schneider P, Schneider G. Counting on natural products for drug design. Nat Chem. 2016;8(6):531-541. doi:10.1038/nchem.2479

14. Chen Y, Tang YM, Yu SL, et al. Advances in the pharmacological activities and mechanisms of diosgenin. Chin J Nat Med. 2015;13 (8):578-587.

15. Yuan B, Byrnes DR, Dinssa FF, Simon JE, Wu Q. Identification of polyphenols, glycoalkaloids, and saponins in Solanum scabrum berries using HPLC-UV/Vis-MS. $\quad J$ Food Sci. 2019;84 (2):235-243. doi:10.1111/1750-3841.14424

16. Krol-Kogus B, Lamine KM, Migas P, Boudjeniba M, KrauzeBaranowska M. HPTLC determination of diosgenin in fenugreek seeds. Acta Pharm. 2018;68(1):97-107. doi:10.2478/acph-20180002

17. Gong J, Fang K, Dong H, Wang D, Hu M, Lu F. Effect of fenugreek on hyperglycaemia and hyperlipidemia in diabetes and prediabetes: a meta-analysis. $J$ Ethnopharmacol. 2016;194:260-268. doi:10.1016/j.jep.2016.08.003

18. Wu FC, Jiang JG. Effects of diosgenin and its derivatives on atherosclerosis. Food Funct. 2019;10(11):7022-7036. doi:10.1039/C9FO00749K
19. Cai B, Zhang Y, Wang Z, et al. Therapeutic potential of diosgenin and its major derivatives against neurological diseases: recent advances. Oxid Med Cell Longev. 2020;2020:3153082. doi:10.1155/2020/3153082

20. Wu S, Zhao F, Zhao J, et al. Dioscin improves postmenopausal osteoporosis through inducing bone formation and inhibiting apoptosis in ovariectomized rats. Biosci Trends. 2019;13 (5):394-401. doi:10.5582/bst.2019.01186

21. Li R, Liu Y, Shi J, et al. Diosgenin regulates cholesterol metabolism in hypercholesterolemic rats by inhibiting NPC1L1 and enhancing ABCG5 and ABCG8. Biochim Biophys Acta Mol Cell Biol Lipids. 2019;1864(8):1124-1133. doi:10.1016/j. bbalip.2019.04.010

22. Tao X, Yin L, Xu L, Peng J. Dioscin: a diverse acting natural compound with therapeutic potential in metabolic diseases, cancer, inflammation and infections. Pharmacol Res. 2018;137:259-269. doi:10.1016/j.phrs.2018.09.022

23. Sethi G, Shanmugam MK, Warrier S, et al. Pro-apoptotic and anti-cancer properties of diosgenin: a comprehensive and critical review. Nutrients. 2018;10(5):5. doi:10.3390/nu10050645

24. Cayen MN, Dvornik D. Effect of diosgenin on lipid metabolism in rats. J Lipid Res. 1979;20(2):162-174. doi:10.1016/S00222275(20)40628-5

25. Liu MX, Zhang FX, Xun LY, Guan DH. Study on regulating blood lipid effects and the mechanism of diosgenin. Arch Tradit Chin Med. 2016;34(04):798-800.

26. Parama D, Boruah M, Kumari Y, et al. Diosgenin, a steroidal saponin, and its analogs: effective therapies against different chronic diseases. Life Sci. 2020;260:118182.

27. Liao AM, Jung H, Yu JW, et al. Synthesis and biological evaluation of arginyl-diosgenin conjugate as a potential bone tissue engineering agent. Chem Biol Drug Des. 2018;91(1):17-28. doi:10.1111/cbdd.13050

28. Chen FX, Zhao MR, Ren BZ, et al. Solubility of diosgenin in different solvents. $J$ Chem Thermodyn. 2012;47:341-346. doi:10.1016/j.jct.2011.11.009

29. Chaudhary SA, Chaudhary PS, Syed BA, et al. Validation of a method for diosgenin extraction from fenugreek (Trigonella foenum-graecum L.). Acta Sci Pol Technol Aliment. 2018;17 (4):377-385.

30. Selim S, Al Jaouni S. Anticancer and apoptotic effects on cell proliferation of diosgenin isolated from Costus speciosus (Koen.) Sm. BMC Complement Altern Med. 2015;15(1):301. doi:10.1186/ s12906-015-0836-8

31. Kim JK, Park SU. An update on the biological and pharmacological activities of diosgenin. EXCLI J. 2018;17:24-28.

32. Li X, Wang Y, Sun J, et al. Chemotaxonomic studies of 12 Dioscorea species from China by UHPLC-QTOF-MS/MS analysis. Phytochem Anal. 2020;31(2):164-182. doi:10.1002/ pca. 2876

33. Herrera T, Navarro Del Hierro J, Fornari T, Reglero G, Martin D. Acid hydrolysis of saponin-rich extracts of quinoa, lentil, fenugreek and soybean to yield sapogenin-rich extracts and other bioactive compounds. J Sci Food Agric. 2019;99(6):3157-3167. doi:10.1002/jsfa.9531

34. Sahu P, Gidwani B, Dhongade HJ. Pharmacological activities of dehydroepiandrosterone: a review. Steroids. 2020;153:108507. doi:10.1016/j.steroids.2019.108507

35. Dong J, Lei C, Lu D, Wang Y. Direct biotransformation of dioscin into diosgenin in rhizome of Dioscorea zingiberensis by penicillium dioscin. Indian $J$ Microbiol. 2015;55(2):200-206. doi:10.1007/s12088-014-0507-3

36. Sauvaire Y, Ribes G, Baccou JC, Loubatieères-Mariani MM. Implication of steroid saponins and sapogenins in the hypocholesterolemic effect of fenugreek. Lipids. 1991;26(3):191-197. doi:10.1007/BF02543970 
37. Wang T, Choi RC, Li J, et al. Antihyperlipidemic effect of protodioscin, an active ingredient isolated from the rhizomes of Dioscorea nipponica. Planta Med. 2010;76(15):1642-1646. doi:10.1055/s-0030-1249960

38. Malinow MR, Elliott WH, McLaughlin P, Upson B. Effects of synthetic glycosides on steroid balance in Macaca fascicularis. $J$ Lipid Res. 1987;28(1):1-9. doi:10.1016/S0022-2275(20) 38729-0

39. Yamanashi Y, Takada T, Yamamoto H, Suzuki H. NPC1L1 facilitates sphingomyelin absorption and regulates diet-induced production of VLDL/LDL-associated S1P. Nutrients. 2020;12 (9):2641. doi:10.3390/nu12092641

40. Tang W, Lin J, Ma Y, et al. Ezetimibe restores biliary cholesterol excretion in mice expressing Niemann-Pick C1-like 1 only in liver. Biochim Biophys Acta. 2011;1811(9):549-555. doi:10.1016/ j.bbalip.2011.05.013

41. Ma HY, Zhao ZT, Wang LJ, Wang Y, Zhou QL, Wang BX. Comparative study on anti-hypercholesterolemia activity of diosgenin and total saponin of Dioscorea panthaica. J Trad Chin Med. 2002;27(7):51-54.

42. Kuang SY, Li Y, Kuang WD. Effects of diosgenin on cholesterol metabolism and caveolin-1 expression in human hepatocyte L-02. Chin Pharm. 2013;24(35):3286-3288.

43. Rhee EJ, Byrne CD, Sung KC. The HDL cholesterol/apolipoprotein A-I ratio: an indicator of cardiovascular disease. Curr Opin Endocrinol Diabetes Obes. 2017;24(2):148-153. doi:10.1097/ MED.0000000000000315

44. Kusano Y, Tsujihara N, Masui H, Kozai H, Takeuchi W. Consumption of Japanese yam improves lipid metabolism in high-cholesterol diet-fed rats. Nutr Sci Vitaminol (Tokyo). 2016;62(5):350-360. doi:10.3177/jnsv.62.350

45. Ma W, Ding H, Gong X, et al. Methyl protodioscin increases ABCA1 expression and cholesterol efflux while inhibiting gene expressions for synthesis of cholesterol and triglycerides by suppressing SREBP transcription and microRNA 33a/b levels. Atherosclerosis. $\quad 2015 ; 239(2): 566-570 . \quad$ doi:10.1016/j. atherosclerosis.2015.02.034

46. Shen WJ, Azhar S, Kraemer FB. SR-B1: a unique multifunctional receptor for cholesterol influx and efflux. Annu Rev Physiol. 2018;80:95-116. doi:10.1146/annurev-physiol-021317-121550

47. Xu J, Xu Y, Xu Y, Yin L, Zhang Y. Global inactivation of carboxylesterase 1 (Ces1/Ces1g) protects against atherosclerosis in Ldlr-/- mice. Sci Rep. 2017;7(1):17845. doi:10.1038/s41598$017-18232-x$

48. Jones H, Alpini G, Francis H. Bile acid signaling and biliary functions. Acta Pharm Sin B. 2015;5(2):123-128. doi:10.1016/j. apsb.2015.01.009

49. Yu L, Lu H, Yang X, et al. Diosgenin alleviates hypercholesterolemia via SRB1/CES-1/CYP7A1/FXR pathway in high-fat diet-fed rats. Toxicol Appl Pharmacol. 2021;412:115388. doi:10.1016/j.taap.2020.115388

50. Gesto DS, Pereira C, Cerqueira NM, Sousa SF. An atomic-level perspective of HMG-CoA-reductase: the target enzyme to treat hypercholesterolemia. Molecules. 2020;25(17):3891. doi:10.3390/ molecules 25173891

51. Fox KM, Tai M-H, Kostev K, Hatz M, Qian Y, Laufs U. Treatment patterns and low-density lipoprotein cholesterol (LDL-C) goal attainment among patients receiving high- or moderate-intensity statins. Clin Res Cardiol. 2017;107 (5):380-388. doi:10.1007/s00392-017-1193-Z

52. Hao S, Xu R, Li D, Zhu Z, Wang T, Liu K. Attenuation of streptozotocin-induced lipid profile anomalies in the heart, brain, and mRNA expression of HMG-CoA reductase by diosgenin in rats. Cell Biochem Biophys. 2015;72(3):741-749. doi:10.1007/ s12013-015-0525-8
53. Uemura T, Goto T, Kang MS, et al. Diosgenin, the main aglycon of fenugreek, inhibits LXRalpha activity in HepG2 cells and decreases plasma and hepatic triglycerides in obese diabetic mice. J Nutr. 2011;141(1):17-23. doi:10.3945/jn.110.125591

54. Pan $\mathrm{CH}$, Tsai $\mathrm{CH}$, Liu FC, et al. Influence of different particle processing on hypocholesterolemic and antiatherogenic activities of yam (Dioscorea pseudojaponica) in cholesterol-fed rabbit model. Sci Food Agric. 2013;93(6):1278-1283. doi:10.1002/ jsfa. 5882

55. Carling D. AMPK signalling in health and disease. Curr Opin Cell Biol. 2017;45:31-37. doi:10.1016/j.ceb.2017.01.005

56. Cheng SL. The Action and Mechanism of Diosgenin Suppress the Nonalcoholic Fatty Liver Disease. Second Military Medical University; 2014.

57. Poudel B, Lim SW, Ki HH, Nepali S, Lee YM, Kim DK. Dioscin inhibits adipogenesis through the AMPK/MAPK pathway in 3T3-L1 cells and modulates fat accumulation in obese mice. Int J Mol Med. 2014;34(5):1401-1408. doi:10.3892/ ijmm.2014.1921

58. Ying F, Cai Y, Wong HK, et al. EP4 emerges as a novel regulator of bile acid synthesis and its activation protects against hypercholesterolemia. Biochim Biophys Acta Mol Cell Biol Lipids. 2018;1863(9):1029-1040. doi:10.1016/j.bbalip.20 18.06.003

59. Liu S, Jing F, Yu C, Gao L, Qin Y, Zhao J. AICAR-induced activation of AMPK inhibits TSH/SREBP-2/HMGCR pathway in liver. PLoS One. 2015;10(5):e0124951. doi:10.1371/journal. pone. 0124951

60. Patel SB, Graf GA, Temel RE. ABCG5 and ABCG8: more than a defense against xenosterols. J Lipid Res. 2018;59(7):1103-1113. doi:10.1194/jlr.R084244

61. Temel RE, Brown JM, Ma Y, et al. Diosgenin stimulation of fecal cholesterol excretion in mice is not NPC1L1 dependent. $J$ Lipid Res. 2009;50(5):915-923. doi:10.1194/jlr.M800631-JLR200

62. Phillips MC. Is ABCA1 a lipid transfer protein? J Lipid Res. 2018. https://pubmed.ncbi.nlm.nih.gov/29305383/ references

63. Lv YC, Yang J, Yao F, et al. Diosgenin inhibits atherosclerosis via suppressing the MiR-19b-induced downregulation of ATP-binding cassette transporter A1. Atherosclerosis. 2015;240 (1):80-89. doi:10.1016/j.atherosclerosis.2015.02.044

64. Gai Y, Li Y, Xu Z, Chen J. Pseudoprotodioscin inhibits SREBPs and microRNA $33 \mathrm{a} / \mathrm{b}$ levels and reduces the gene expression regarding the synthesis of cholesterol and triglycerides. Fitoterapia. 2019;139:104393. doi:10.1016/j.fitote.2019.104393

65. Marrocco I, Altieri F, Peluso I. Measurement and clinical significance of biomarkers of oxidative stress in humans. Oxid Med Cell Longev. 2017;2017:6501046. doi:10.1155/2017/6501046

66. Gupta DD, Mishra S, Verma SS, et al. Evaluation of antioxidant, anti-inflammatory and anticancer activities of diosgenin enriched Paris polyphylla rhizome extract of Indian Himalayan landraces. $J \quad$ Ethnopharmacol. 2021;270:113842. doi:10.1016/j. jep.2021.113842

67. Pi WX, Feng XP, Ye LH, Cai BC. Combination of morroniside and diosgenin prevents high glucose-induced cardiomyocytes apoptosis. Molecules. 2017;22(1):163. doi:10.3390/ molecules 22010163

68. Sangeetha MK, ShriShri Mal N, Atmaja K, Sali VK, Vasanthi HR. PPAR's and diosgenin a chemico biological insight in NIDDM. Chem Biol Interact. 2013;206(2):403-410. doi:10.1016/j.cbi.2013.08.014

69. Manivannan J, Balamurugan E, Silambarasan T, Raja B. Diosgenin improves vascular function by increasing aortic eNOS expression, normalize dyslipidemia and ACE activity in chronic renal failure rats. Mol Cell Biochem. 2013;384(12):113-120. doi:10.1007/s11010-013-1788-2 
70. Xu T, Zheng $\mathrm{L}, \mathrm{Xu} \mathrm{L}$, et al. Protective effects of dioscin against alcohol-induced liver injury. Arch Toxicol. 2014;88(3):739-753. doi:10.1007/s00204-013-1148-8

71. Son IS, Kim JH, Sohn HY, Son KH, Kim JS, Kwon CS Antioxidative and hypolipidemic effects of diosgenin, a steroidal saponin of yam (Dioscorea spp.), on high-cholesterol fed rats. Biosci Biotechnol Biochem. 2007;71(12):3063-3071. doi:10.1271/bbb.70472

72. Uemura T, Hirai S, Mizoguchi N, et al. Diosgenin present in fenugreek improves glucose metabolism by promoting adipocyte differentiation and inhibiting inflammation in adipose tissues. $\mathrm{Mol}$ Nutr Food Res. 2010;54(11):1596-1608. doi:10.1002/ mnfr.200900609

73. Koerner CM, Roberts BS, Neher SB. Endoplasmic reticulum quality control in lipoprotein metabolism. Mol Cell Endocrinol. 2019;498:110547. doi:10.1016/j.mce.2019.110547

74. Gong G, Qin Y, Huang W, et al. Protective effects of diosgenin in the hyperlipidemic rat model and in human vascular endothelial cells against hydrogen peroxide-induced apoptosis. Chem Biol Interact. 2010;184(3):366-375. doi:10.1016/j.cbi.2010.02.005

75. Matsuo Y, Matsumoto K, Inaba N, Mimaki Y. Daisaikoto inhibits pancreatic lipase activity and decreases serum triglyceride levels in mice. Biol Pharm Bull. 2018;41(9):1485-1488. doi:10.1248/ bpb.b18-00324

76. Kwon CS, Sohn HY, Kim SH, et al. Anti-obesity effect of Dioscorea nipponica Makino with lipase-inhibitory activity in rodents. Biosci Biotechnol Biochem. 2003;67(7):1451-1456. doi:10.1271/bbb.67.1451

77. Navarro Del Hierro J, Casado-Hidalgo G, Reglero G, Martin D. The hydrolysis of saponin-rich extracts from fenugreek and quinoa improves their pancreatic lipase inhibitory activity and hypocholesterolemic effect. Food Chem. 2021;338:128113. doi:10.1016/j.foodchem.2020.128113

78. Zhang F, Sun W, Chen J, et al. SREBP-2, a new target of metformin? Drug Des Devel Ther. 2018;12:4163-4170. doi:10.2147/DDDT.S190094

79. Shimano H, Sato R. SREBP-regulated lipid metabolism: convergent physiology - divergent pathophysiology. Nat Rev Endocrinol. 2017;13(12):710-730.

80. Schulman IG. Liver $X$ receptors link lipid metabolism and inflammation. FEBS Lett. 2017;591(19):2978. doi:10.1002/18733468.12702

81. Wang B, Tontonoz P. Liver X receptors in lipid signalling and membrane homeostasis. Nat Rev Endocrinol. 2018;14 (8):452-463. doi:10.1038/s41574-018-0037-x

82. de la Rosa Rodriguez MA, Kersten S. Regulation of lipid droplet-associated proteins by peroxisome proliferator-activated receptors. Biochim Biophys Acta Mol Cell Biol Lipids. 2017;1862 (10 Pt B):1212-1220. doi:10.1016/j.bbalip.2017.07.007

83. Kersten S, Stienstra R. The role and regulation of the peroxisome proliferator activated receptor alpha in human liver. Biochimie. 2017;136:75-84. doi:10.1016/j.biochi.2016.12.019

84. Debose-Boyd RA, Ye J. SREBPs in lipid metabolism, insulin signaling, and beyond. Trends Biochem Sci. 2018;43(5):358368. doi: 10.1016/j.tibs.2018.01.005.

85. Li X, Li Y, Yang W, et al. SREBP-1c overexpression induces triglycerides accumulation through increasing lipid synthesis and decreasing lipid oxidation and VLDL assembly in bovine hepatocytes. J Steroid Biochem Mol Biol. 2014;143:174-182. doi:10.1016/j.jsbmb.2014.02.009

86. Hua S, Li Y, Su L, Liu X. Diosgenin ameliorates gestational diabetes through inhibition of sterol regulatory element-binding protein-1. Biomed Pharmacother. 2016;84:1460-1465. doi:10.1016/j.biopha.2016.10.049
87. Yao H, Tao X, Xu L, et al. Dioscin alleviates non-alcoholic fatty liver disease through adjusting lipid metabolism via SIRT1/ AMPK signaling pathway. Pharmacol Res. 2018;131:51-60. doi:10.1016/j.phrs.2018.03.017

88. Mohammad-Sadeghipour M, Mahmoodi M, Noroozi Karimabad M, Mirzaei MR, Hajizadeh MR. Diosgenin and 4-hydroxyisoleucine from fenugreek are regulators of genes involved in lipid metabolism in the human colorectal cancer cell line SW480. Cell J. 2021;22(4):514-522.

89. Schultz JR, Tu H, Luk A, et al. Role of LXRs in control of lipogenesis. Genes Dev. 2000;14(22):2831-2838. doi:10.1101/ gad. 850400

90. Xu HF, Luo J, Zhang XY, Li J, Bionaz M. Activation of liver $\mathrm{X}$ receptor promotes fatty acid synthesis in goat mammary epithelial cells via modulation of SREBP1 expression. J Dairy Sci. 2019;102(4):3544-3555. doi:10.3168/jds.2018-15538

91. Cheng S, Liang S, Liu Q, et al. Diosgenin prevents high-fat diet-induced rat non-alcoholic fatty liver disease through the AMPK and LXR signaling pathways. Int $J$ Mol Med. 2018;41 (2):1089-1095.

92. Cheng HS, Tan WR, Low ZS, Marvalim C, Lee JYH, Tan NS. Exploration and development of PPAR modulators in health and disease: an update of clinical evidence. Int J Mol Sci. 2019;20 (20):5055. doi:10.3390/ijms20205055

93. Mirza AZ, Althagafi II, Shamshad H. Role of PPAR receptor in different diseases and their ligands: physiological importance and clinical implications. Eur J Med Chem. 2019;166:502-513. doi:10.1016/j.ejmech.2019.01.067

94. Bougarne N, Weyers B, Desmet SJ, et al. Molecular actions of PPAR $\alpha$ in lipid metabolism and inflammation. Endocr Rev. 2018;39(5):760-802.

95. Janani C, Ranjitha Kumari BD. PPAR gamma gene-a review. Diabetes Metab Syndr. 2015;9(1):46-50. doi:10.1016/j. dsx.2014.09.015

96. Alam F, Islam MA, Mohamed M, et al. Efficacy and safety of pioglitazone monotherapy in type 2 diabetes mellitus: a systematic review and meta-analysis of randomised controlled trials. Sci Rep. 2019;9(1):5389. doi:10.1038/s41598-019-41854-2

97. Wang X, Liu J, Long Z, et al. Effect of diosgenin on metabolic dysfunction: role of ERbeta in the regulation of PPARgamma. Toxicol Appl Pharmacol. 2015;289(2):286-296. doi:10.1016/j. taap.2015.09.015

98. Zhang Y, Cui Y, Wang XL, Shang X, Xie ML. PPAR $\alpha / \gamma$ agonists and antagonists differently affect hepatic lipid metabolism, oxidative stress and inflammatory cytokine production in steatohepatitic rats. Cytokine. 2015;75(1):127-135. doi:10.1016/j. cyto.2015.05.031

99. Nanjan MJ, Mohammed M, Prashantha Kumar BR, Chandrasekar MJN. Thiazolidinediones as antidiabetic agents: a critical review. Bioorg Chem. 2018;77:548-567. doi:10.1016/j. bioorg.2018.02.009

100. Gan Q, Wang J, Hu J, et al. The role of diosgenin in diabetes and diabetic complications. $J$ Steroid Biochem Mol Biol. 2020;198:105575. doi:10.1016/j.jsbmb.2019.105575

101. Zhao S, Niu F, Xu CY, et al. Diosgenin prevents bone loss on retinoic acid-induced osteoporosis in rats. Ir J Med Sci. 2016;185 (3):581-587. doi:10.1007/s11845-015-1309-2

102. Yin H, Zhang MJ, An RF, Zhou J, Huang XF. Diosgenin derivatives as potential antitumor agents: synthesis, cytotoxicity, and mechanism of action. J Nat Prod. 2020;84(3):616-29.

103. Manda VK, Avula B, Ali Z, et al. Characterization of in vitro ADME properties of diosgenin and dioscin from Dioscorea villosa. Planta Med. 2013;79(15):1421-1428. doi:10.1055/ s-0033-1336521 
104. Liu P, Zhou JY, Chang JH, et al. Soluplus-mediated diosgenin amorphous solid dispersion with high solubility and high stability: development, characterization and oral bioavailability. Drug Des Devel Ther. 2020;14:2959-2975. doi:10.2147/DDDT.S253405

105. Schittny A, Huwyler J, Puchkov M. Mechanisms of increased bioavailability through amorphous solid dispersions: a review. Drug Deliv. 2020;27(1):110-127. doi:10.1080/10717544.2019.1704940

106. Banerjee S, Bhattacharjee P, Kar A, Mukherjee PK. LC-MS/MS analysis and network pharmacology of Trigonella foenum-graecum - a plant from Ayurveda against hyperlipidemia and hyperglycemia with combination synergy. Phytomedicine. 2019;60:152944. doi:10.1016/j.phymed.2019.152944
107. Ren Y, Wang Z, Wu C, et al. Ultrahigh-performance liquid chromatography with tandem mass spectrometry for the determination of 10 alkaloids in beagle plasma after the oral administration of the three Coptidis rhizoma extracts. $J$ Ethnopharmacol. 2019;239:111896. doi:10.1016/j.jep.2019.111896

108. Sozen E, Yazgan B, Sahin A, Ince U, Ozer NK. High cholesterol diet-induced changes in oxysterol and scavenger receptor levels in heart tissue. Oxid Med Cell Longev. 2018;2018:8520746. doi: $10.1155 / 2018 / 8520746$

\section{Publish your work in this journal}

Diabetes, Metabolic Syndrome and Obesity: Targets and Therapy is an international, peer-reviewed open-access journal committed to the rapid publication of the latest laboratory and clinical findings in the fields of diabetes, metabolic syndrome and obesity research. Original research, review, case reports, hypothesis formation, expert opinion and commentaries are all considered for publication. The manuscript management system is completely online and includes a very quick and fair peer-review system, which is all easy to use. Visit http://www.dovepress.com/testimonials.php to read real quotes from published authors. 